\title{
Smart Irrigation using CARRIOTS IoT Platform and IFFT Algorithm for Agricultural Field
}

\author{
K.Ranjitha ${ }^{1}$, P.Sivakumar ${ }^{2}$, M.Monica ${ }^{3}$ \\ ${ }^{1}$ Rajalakshmi Institute of Technology, India, ranjitha.k@ritchennai.edu.in \\ ${ }^{2}$ Rajalakshmi Engineering College, India, sivakumar.p@rajalakshmi.edu.in \\ ${ }^{3}$ Rajalakshmi Institute of Technology, India, monicam@ @itchennai.edu.in
}

\begin{abstract}
The scope of water resource in agriculture is a rising issue in the country. The automated irrigation in agricultural field offers solution for collection and analysis of data using sensor's measurements and can be transferred to IoT (Internet of Things) for interpretation of information and feedback to system in the future of agriculture. Using IoT, data is not only acquired from the sensors but also used for tracking purposes to take corrective actions when the signals show a value out of the range. Several actions to alert the user need to be notified immediately and hence this entire smart irrigation system is built using Carriots and Inverse Fast Fourier Transform (IFFT). Even though Carriots has a built-in email system to alert the user, a platform of IFFT is used to as it provides several integration services that we can use and integrate into our future automation in agriculture. In this work, we have presented moisture sensors dipped into the sand for observing the wetness condition of sand almost around every plant which is essential for farming without wasting water. The signals from the sensor are used in governing the water pump and solenoid valves. Every solenoid valve is coupled with each plant to manipulate the water supply. The sensors give signal depending on the moisture condition and accordingly the arduino controls the solenoid valves and also sends the data to the cloud for sending notifications.
\end{abstract}

Key words: Arduino UNO, Internet of Things, Smart irrigation, Simple Link Wi-Fi module

\section{INTRODUCTION}

In INDIA a large scale of income is only from agriculture sector and most people depend on agriculture for their daily livelihood. Being a developing country, yet most of the irrigation systems in the major outskirts of India are well irrigation or solar powered motor pumps. Irrigating the soil relies on soil properties like moisture, humidity, type of crop and area of land that requires to be watered. Recent technological development concentrates more for irrigation purposes. In India rural area with agricultural lands take in power supply generally in non-peak hours with often interrupting power cuts and low voltage hosts in a major trouble to farmers. The maximum utilization of power supply starts around 7 am for daily works. There is wastage of water and electricity in case the farmer fails to attend the irrigation and furthermore, over watering leads to soil becoming inadequate for farming certain crops. A quick and automatic irrigation system is required to control and monitor the irrigation of land to avoid all discrepancies and to save the natural resource water. This automated irrigation system built here is simple and easy to install and can be operated even by a layman. This system uses only standard $\mathrm{ON}$ and OFF to control water motor. The programming language Python is been used for automation purpose.

This system has been developed for an automated irrigation system for the farmers on the basis of wireless sensor network. This system repeatedly monitors the parameters temperature, humidity, and moisture of soil [1],[5]. An algorithm with threshold values of soil moisture is to be maintained continuously. System starts or stops irrigation supported by wetness content of the soil. This system proposes low cost moisture sensor based data acquisition system required for automated irrigation system. The authors have developed associate electric resistance primarily based wetness device [4],[8].

In this paper sensors works on the change of impedance between two electrodes kept in soil. This paper represents irrigation management system using WSN and water pumps [2],[9],[10],[11]. Water level sensors are linked to main canals, and flow sensor is joined with water pump. These sensors are connected to wireless entryway that sends knowledge sporadically to internet server.

Database connected to web server, monitors irrigation water level at all main plants. The web based IMS analyze the data stored in database and compares with specified values. Then it (IMS) sends SMS to cultivators and field operation engineers to make them apprehensive of water demand during that time [3]. In this work soil moisture sensors are placed in the agriculture field which measures the soil's moisture value periodically, water level in the tank and well-water through mobile data communication network. The web servers use intelligent software to analyze mobile data [6], [7]. 


\section{EMBEDDED SYSTEM}

Embedded systems are PC systems that are a piece of bigger systems and they play out a portion of the prerequisites of these systems. A few examples of embedded systems are handy control systems, they can be in mechanical form of control systems, mobile phones, or like tiny sensor controllers. The scope of embedded systems wraps a vast of PC systems from ultra- little PC based gadgets to extensive systems checking and controlling complex procedures. The overpowering number of PC systems has a place with embedded systems: $99 \%$ of all registering units have a place with embedded systems today.

Arduino is an electronic scaffold with built in easy to use hardware. It is open source software. Arduino UNO is one of the most easily available low-cost Arduino board. The Arduino is an embedded system. Various pins on the Arduino are used to read or write values on to the system. Many types of micro controllers are available in the market. Some of them are Parallax Basic Stamp, Netmedia's BX-24, Phidgets, MIT's Handyboard that provide the same functionalities but Arduino holds the following advantage over them:

- Inexpensive

- Cross Platform (Linux, Mac OS, Windows)

-Simple clear programming environment

\section{DESIGN OF SYSTEM}

\subsection{Soil moisture sensor}

The Soil Moisture Sensor is affiliated with a controller that tracks soil dampness content in the roots for every periodical instants and ducks the cycle if moisture content is over a specified threshold point.

\subsection{Use of sensors}

The Soil Moisture Sensor (SMS) is a sensor connected to the irrigation system controller that measures the soil moisture content. The soil moisture sensor reads the value of moisture content in the soil and prints it on the console to view the values. A threshold value is set at the beginning depending upon the plant being watered and region in which it is being watered. The soil moisture sensors read the value once within a stipulated delay time. Once the moisture is above the user defined threshold value, the sensor stops reading the value and the control passes on to the Arduino which switches on the pump to start the watering of the system.

\subsection{Data Acquisition}

Data Acquisition is the administration of various electrical or electronic signals from appliances, for example clocks, sensors, and strong state circuits with the objective of investigating, communicating or possibly controlling frameworks and procedures. Information securing instrument sorts incorporate PC sheets, instruments or frameworks, data loggers or recorders, outline recorders, input modules, yield modules, and I/O modules. In this work presented, data is acquired by usage of the Soil Moisture Sensors. It works on the precept of Dielectric permittivity. The dielectric permittivity is the amount of electricity that can be passed through the soil. The dielectric permittivity is a function of water content present in the soil. Hence by measuring the dielectric permittivity we could measure the soil moisture content. A vestibule point is set and data is secured till it purviews the threshold value. Once it has purview the vestibule point the soil moisture sensor circumvents for one cycle.

\subsection{Decision regarding threshold value}

The soil moisture sensor is buried in the soil and water is applied to the soil. To fix the threshold value a certain level of standing water (at least one inch) is put on the soil. After a day, the vestibule point of the soil moisture is read and set as a threshold value. A $20 \%$ reduction can be done on the moisture level to allow a little more time for the water to seep in.

\section{PROPOSED SYSTEM}

Figure 1 shows the proposed work which involves the use of solar for powering the motor and associated components such as IoT and Cloud computing for monitoring and controlling the irrigation process.

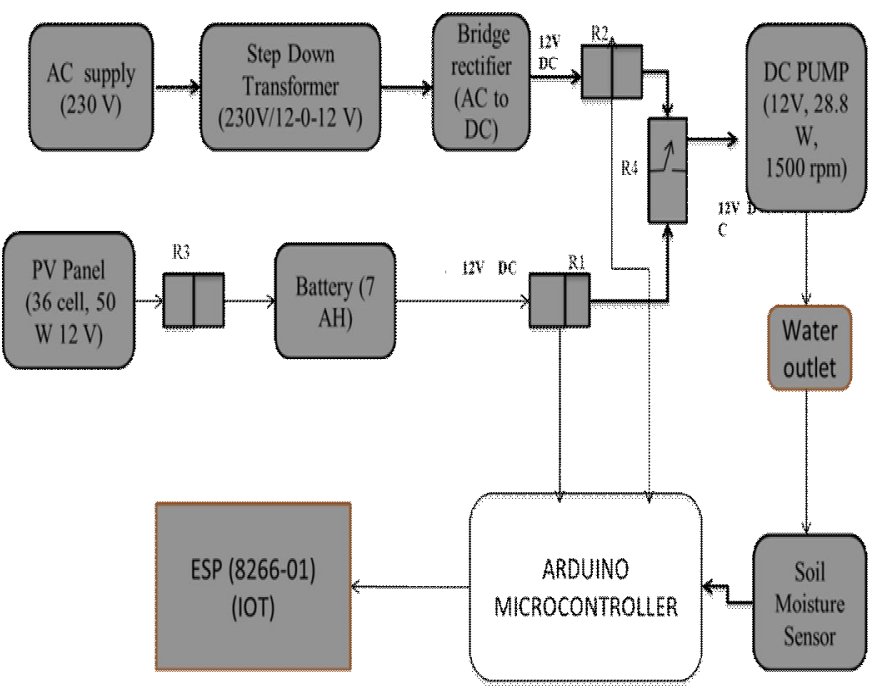

Figure 1: Block diagram of proposed system

\subsection{Step down Transformer}

The step down transformer is used to reduce high voltages to much lower values. This particular step down transformer lowers voltage from $230 \mathrm{~V}$ to $12 \mathrm{~V}$. It ensures that the input to the bridge rectifier is always maintained at a constant value of $12 \mathrm{~V}$, thus reducing the risk of voltage fluctuations within the system 
K.Ranjitha et al., International Journal of Emerging Trends in Engineering Research, 8(5), May 2020, 1834- 1838

\subsection{Solar PV Panel}

Solar panel operates based on the principle of converting light energy into electrical energy. When solar radiation is absorbed by specific semiconductor material, the electrons in atoms gain higher energy state, permitting them to flow through the material in order to produce electricity. This process of converting light energy to electrical energy is called the photovoltaic (PV) effect.

\subsection{Soil Sensor}

Soil sensor is used to measure the moisture content of the soil. In soil sensor, the moisture in the soil is proportional to the dielectric permittivity of the medium. Soil sensor makes use of the capacitance to sense the volumetric water content. Difficulties encountered in the data processing of multiple soil sensor are lagging in continuity of the information, delayed responses, non-uniform monitoring. Wireless Sensor Network (WSN), Smart sensors are the methods to overcome the problems associated with the data processing of multiple soil sensors.

\subsection{Pump}

A $12 \mathrm{~V} \mathrm{dc}$ motor is used with the pump. By activating the motor driver circuit by the read value of the Arduino board with the set reference value, the pump will automatically turn on and turn off.

\subsection{Relay}

It is used to switch on and switch off the pump according to the water requirement of the soil

\subsection{Freewheeling diode}

Since the relay coil cannot change its current instantly, a diode is placed parallel to the relay coil. This diode will provide a path for the current when the coil is switched off. Otherwise, a sudden voltage spike will occur on the switch contacts or will destroy the switching transistors of the motor driven circuit

\subsection{IoT - ESP (8266-01)}

The ESP (8266 - 01) is a very small module in size and concedes microcontrollers to interface to a Wi-Fi network and concludes all the uncomplicated TCP/IP connections using Hayes-style rules. However, at first there was almost no English-language memorandum on the chip and the commands it accepted. The nominal price and the fact that there were very few external components on the module, which suggested that it could eventually be very inexpensive in mass number of volume too.

\section{IMPLEMENTATION}

This system consists of various sensors such as Soil moisture sensor to measure water content of soil and temperature sensor to detect the temperature. DC motor based pump is meant for Irrigation purpose. The soil moisture electrode is inserted in soil and this aids in checking the wetness level of the soil. The set point for soil moisture sensor \& temperature sensor is $1000 \& 35$ degree Celsius respectively. If the soil moisture value is less than 1000 , an alert message is sent "MOTOR ON" to the mobile then water is provided until the plants reach the wetness level. If the soil moisture value is less than 250, an alert message is sent "MOTOR OFF" to the mobile then water supply will be stopped. The Arduino will send all the information to the server using Wi-Fi module.

The installation of the machine-driven irrigation system is finished. The system is checked using simulation in Proteus software before on the field working. The system works properly for the commands given through the Arduino controller. If the soil is dry, an alert message is sent "MOTOR ON" to the mobile through voice or text water pump starts which leads to water to flow. If the soil is wet, an alert message is sent "MOTOR OFF" to the mobile and then water pump is turned off and water flow stop. This work tries to establish a efficient way of watering the crops during difficult times by the use of scheduling also. A scheduling program is also dumped into the Arduino board in case of climate changes. Here in this system there is no manual intervention and the irrigation process is sensible and without much labor involved. The primary applications of this project are for farmers and gardeners who don't have enough time to water crops/plants. The farmers are facing major problems in watering their agriculture fields as the power supply now a days plays a major role in India. The interrupting power cuts, low voltages and increased billing amount of electricity has lead to an automated system. The energy supplied to the motor through Solar panel is a great relief from the increasing electricity bills. The controller also switches the relay between the supply ie., solar and AC supply. During gloomy days where solar energy is not available the controller switches in between the available source of supply. This system also features a customized addition of sensors in the future for advocating many other parameters such as power efficiency, cost effectiveness, scalability end ease of use.

\section{SIMULATION}

The software used here is Proteus. It provides number of libraries to make the programming of the system so simple. The prototype of controller AtMega 328 is programmed which contains some resistance value ranging from 0 to 1023 . If 0 it means fully wet condition and 1023 means fully dry condition. A value is being set in between these two values which will decide whether the pump has to be switched on or off. This is simulated in proteus software and the output is shown in Figure 2. 


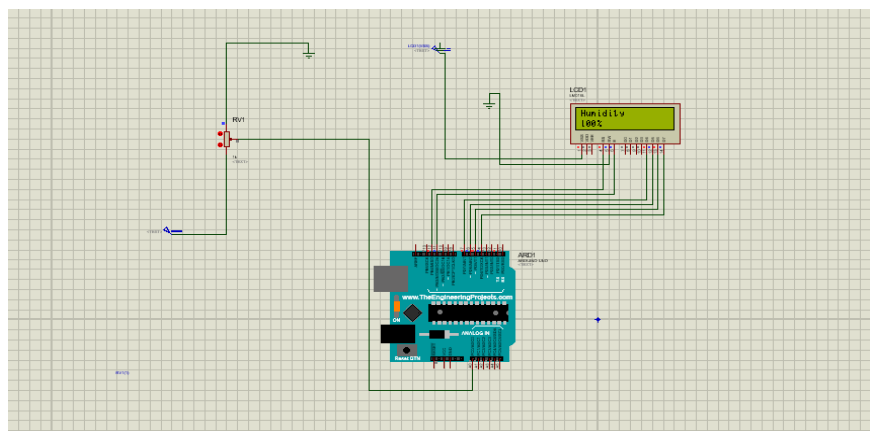

Figure 2: Simulation of Soil moisture sensor

\section{HARDWARE}

This work has fewer components since it is a demonstration about the work over a very small area with fewer plants. Figure 3 shows the hardware developed for automated irrigation system to control the motor using the vestibule point of soil wetness as point to switch ON or OFF the motor and switch between the power supply whichever is available. If the area of irrigation increases we can use more number of moisture sensors and temperature sensors so that it will work according to the climatic conditions. Resistance varies with moisture. As the soil moisture sensor is analog, an ADC in Arduino is used to convert into digital form which will represent the resistance. Dry soil will have the maximum resistance and wet soil will have the minimum resistance. After sensing the value it will automatically decide whether the pump has to be turned on or turned-off. The pump will turn on as the current passes through the relay coil and it will get energized and switches off as the value reaches the threshold value.

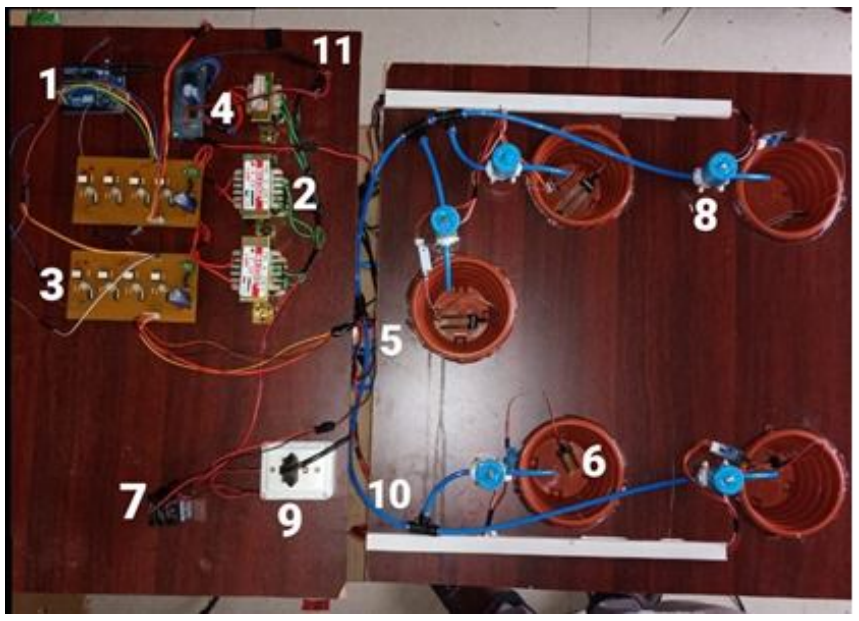

Figure 3: Constructed Hardware for a small scale irrigation.

\section{CONCLUSION}

India is a country with more population relying on agriculture on its land with irrigation for crops being a crisis when monsoon is absent for a period. Optimal farming gives more crop yield. So this work has been designed for a smart irrigation system based on IoT with sensor of humidity. It monitors the moisture content levels of soil in farm and can generate moisture level data through sensors. Accordingly irrigation based decisions are taken by system automatically to start water pump and to divert the flow of pump motor for irrigation. Designed system can irrigate field with lesser amount of water. This work can be extended with additional features in the near future with automatic billing for usage of electricity and notifying the farmers about the nutrient content in the soil as the nutrients are lost over a period of time.

\section{REFERENCES}

1. Hemalatha, Deepika, Dhanalakshmi, Dharanipriya, Divya. Internet of Things (IoT) Based Smart Irrigation, Journal of Advanced Research in Biology Engineering Science and Technology, Vol. 2, pp. 129-132, February 2016.

2. Yogesh G. Gawali, Devendra S. Chaudhari, Hitendra C. Chaudhari. Automated Irrigation System using Wireless Sensor Network, International Journal of Advanced Research in Electronics and Communication Engineering, ISSN: 2278 - 909X Vol. 5, Issue 6, June 2016.

3. Pavithra, D.M.S.Srinath. GSM based Automatic Irrigation Control System for Efficient use of Resources and crop Planning by using an Android Mobile, IOSR Journal of Mechanical and Civil Engineering, ), e-ISSN: 2278-1684,p-ISSN: 2320-334X, Volume 11, Issue 4 Ver. I (Jul- Aug. 2014), PP 49-55. https://doi.org/10.9790/1684-11414955

4. P.Archana, R.Priya. Design and Implementation of Automatic Plant Watering System, International Journal of Advanced Engineering and Global Technology, Vol.04, pp. 1567-1570, ,January 2016.

5. Venkata Naga Rohit Gunturi. Microcontroller based automatic plant irrigation System, International Journal of Advancement in Research and Technology, Vol.2, issue 4, April 2013 pp. 194-1986.

6. Suraj S. Avatade, Dhanure S.P. Irrigation System Using wireless Sensor network and GPRS, International Journal of Advance Research in Computer and Communication Engineering, Vol.4, issue 4, May 2015 pp.521-524. https://doi.org/10.17148/IJARCCE.2015.45111

7. Purnima, SRN, Reddy. Design of a remote monitoring and control System with Automatic Irrigation System using GSM blue-tooth, International Journal of Computer Applications, Vol. 47 No 12, June 2012. https://doi.org/10.5120/7238-9355

8. Karan Kansara, Vishal Zaveri, Shreyans Shah1, Sandip Delwadkar, Kaushal Jani. Sensor based Automated Irrigation System with IOT: A Technical Review, 
K.Ranjitha et al., International Journal of Emerging Trends in Engineering Research, 8(5), May 2020, 1834- 1838

International Journal of Computer Science and Information Technologies, Vol.6 (6), pp. 5331-5333, 2015.

9. Janus Jade A. Basa et.al, Smart Inventory Management System for Photovoltaic-Powered Freezer Using Wireless Sensor Network, International Journal of Emerging Trends in Engineering Research, Vol.7, Issue 10, October 2019.

https://doi.org/10.30534/ijeter/2019/057102019

10. Gunawan Wang, Natanael Alamas and Marcelina Anggraeni. The Use of Internet of Things and Big Data to Improve Customer Data in Insurance Company, International Journal of Emerging Trends in Engineering Research, Vol.7, No.12, Dec 2019. https://doi.org/10.30534/ijeter/2019/047122019

11. K. Ruth Ramya et.al., An Efficient and Secured Biometric Authentication for IoT, International Journal of Emerging Trends in Engineering Research, Vol.7, No.11, Nov 2019.

https://doi.org/10.30534/ijeter/2019/327112019 